\title{
EFEITO DA MONENSINA SÓDICA SOBRE O PERFIL METABÓLICO DE OVELHAS ANTES E APÓS O PARTO
}

\section{EFFECT OF MONENSIN SODIUM ON METABOLIC PROFILE OF EWES BEFORE AND POSPARTUM}

\author{
Elizabeth Hortêncio Ferreira Lima ${ }^{1}$ \\ Carla Lopes Mendonça ${ }^{2}$ \\ Jobson Filipe de Paula Cajueiro ${ }^{2}$ \\ Cleyton Charles Dantas Carvalho ${ }^{3}$ \\ Pierre Castro Soares ${ }^{3}$ \\ Rodolfo José Cavalcanti Souto ${ }^{2}$ \\ Ana Rita Fraga Drummond 4 \\ José Augusto Bastos Afonso²*
}

${ }^{11}$ Programa de Pós-Graduação em Sanidade e Reprodução de Ruminantes,Universidade Federal Rural de
Pernambuco, Recife, PE, Brasil.
${ }^{2}$ Clínica de Bovinos de Garanhuns, Universidade Federal Rural de Pernambuco, Recife, PE, Brasil.
${ }^{3}$ Departamento de Medicina Veterinária, Universidade Federal Rural de Pernambuco, Recife, PE, Brasil.
${ }^{4}$ Laboratório de Fluidos, Instituto Tecnológico de Pernambuco (ITEP), Recife, PE, Brasil
"Autor para correspondência: afonsojab@oi.com.br

\section{Resumo}

O estudo foi realizado com o intuito de avaliar o efeito da monensina, suplementada a partir de 60 dias antes do parto (dap) e por 30 dias pós-parto, sobre o perfil metabólico e hormonal de ovelhas. As ovelhas prenhas $(\mathrm{n}=13)$, foram divididas, de forma aleatória, em dois grupos, um que recebeu a monensina $(n=7)(30 \mathrm{mg} / \mathrm{dia})$ e o controle $(n=6)$. Amostras de sangue e fluido ruminal foram colhidas aos $60,50,40,30,20$ e 10 dias antes do parto, no momento do parto e nos 10,20 e 30 dias pós-parto. As variáveis mensuradas foram: glicose, frutosamina, ácidos graxos não esterificados (AGNEs), $\beta$-hidroxibutirato, colesterol, triglicérides, proteína total, albumina, ureia e pesquisa de corpos cetônicos na urina. As determinações hormonais foram cortisol e a insulina. No fluido ruminal foi determinado o $\mathrm{pH}$ e a concentração dos ácidos graxos voláteis. Na análise estatística foi empregada a ANOVA e estudo de correlação $(\mathrm{P}<0,05)$. A monensina elevou $(\mathrm{P}<0,05)$ a concentração do propionato no rúmen e frutosamina e insulina no sangue. A administração da monensina promoveu melhora em alguns indicadores do balanço energético.

Palavras-chave: ácidos graxos voláteis; ionóforo; ovinos; perfil energético; perfil proteico.

\begin{abstract}
The study was carried out to analyze the effect of monensin supplementation during 60 days prior to parturition, and 30 days postpartum, on the metabolic and hormonal profile of ewes. Pregnant ewes $(n=13)$ were randomly divided into two groups: monensin group $(n=7 ; 30 \mathrm{mg} /$ day $)$ and control group $(n=6)$. Blood and ruminal fluid samples were collected $60,50,40,30,20$ and 10 days prior to parturition, at the time of parturition and on 10,20 and 30 days postpartum. The following variables were analyzed: glucose, fructosamine, non-esterfied fatty acids, $\beta$-hydroxybutyrate, cholesterol, triglycerides, total protein, albumin, urea and ketone bodies in the urine. The hormonal determinations were cortisol and insulin. The analysis of the ruminal fluid involved $\mathrm{pH}$ and concentration of volatile fatty acids. The statistical analysis involved ANOVA and correlation studies $(\mathrm{P}<0,05)$. Monensin increased $(\mathrm{P}<0,05)$ the propionic acid concentration in the rumen and blood fructosamine and insulin. The administration of monensin improved some indicators of energy balance.
\end{abstract}


Keywords: ionophor; profile energy; profile protein; sheep; volatile fatty acids.

Recebido em: 17 fevereiro 2014

Aceito em: 17 setembro 2015

\section{Introdução}

A expressão do crescimento da ovinocultura no Brasil vem ocorrendo nos últimos anos, como consequência da melhoria dos padrões genéticos, das boas práticas sanitárias, do adequado manejo alimentar e do bem estar animal, resultando no equilíbrio produtivo adequado. Todavia, com o intuito de atender a demanda cada vez mais crescente do mercado, na produção de ovinos, maiores índices de produtividade são obtidos por meio de práticas intensivas de manejo que, em algumas situações rompem este equilíbrio, gerando a possibilidade da ocorrência de diferentes distúrbios ${ }^{(1)}$.

O período final da gestação e o início da lactação constituem as fases mais críticas no ciclo produtivo das ovelhas, quando a ingestão de alimentos geralmente é insuficiente para atender as necessidades nutricionais dos animais. Um manejo inadequado dessas fêmeas pode influenciar na sua produtividade e saúde ${ }^{(2)}$.

Entre as doenças metabólicas que promovem impactos negativos para o produtor, merece destaque a toxemia da prenhez, que acomete as ovelhas pela inabilidade do alimento ofertado atender de maneira adequada a maior necessidade de glicose, principalmente quando prenhas com mais de um feto. Os transtornos na glicemia e a hipercetonemia são os distúrbios metabólicos primários na toxemia da prenhez ${ }^{(3-5)}$. Práticas adequadas de manejo alimentar no período de transição são cruciais para a melhoria na produção das ovelhas, evitando o surgimento de balanço energético negativo, comum neste tipo de transtorno metabólico.

Uma prática considerada de bom potencial, com intuito de minimizar o impacto do balanço energético negativo, é a inclusão de ionóforos na dieta durante o pré-parto. Entre eles, o mais extensivamente empregado é a monensina sódica, principalmente na espécie bovina. Monensina é produzida pelo Streptomyces cinnamonensis, cuja principal ação se dá por meio da alteração da flora ruminal, modificando o padrão da fermentação ruminal. Este ionóforo inibe as bactérias Gram positivas e preserva as Gram negativas, diminuindo a produção de metano, acetato e butirato e intensificando a produção de propionato, considerado o principal precursor gliconeogênico em ruminantes ${ }^{(6,7)}$.

Ao longo destes últimos anos, vários foram os estudos sobre o emprego da monensina sódica na produção de bovinos de corte e leite ${ }^{(8)}$. No que diz respeito à suplementação deste ionóforo em ovelhas, poucos trabalhos relataram a sua administração apenas nos momentos que antecederam o parto ${ }^{(9,10)}$. Diante do exposto, este estudo teve como objetivo avaliar o efeito da suplementação da monensina sódica na dieta antes, durante e após o parto sobre o perfil metabólico, hormonal e ruminal de ovelhas.

\section{Material e Métodos}

O experimento foi realizado no aprisco de experimentação de pequenos ruminantes da Clínica de Bovinos, Campus Garanhuns, UFRPE. Foram utilizadas 13 ovelhas gestantes, clinicamente sadias, primíparas e multíparas (segunda cria), da raça Santa Inês, com peso médio de $50 \mathrm{~kg}$, vacinadas (Covexin 9, Coopers Brasil Ltda) e desverminadas (Cydectin oral, Fort Dodge).

As ovelhas foram distribuídas aleatoriamente em dois grupos: G1, grupo que recebeu a monensina sódica $(n=7)$ e $G 2$, grupo controle $(n=6)$. Ao grupo controle foi fornecido capim elefante (Pennisetum purpureum), tifton (Cynodom sp.), ração balanceada na proporção de $400 \mathrm{~g} / \mathrm{animal} / \mathrm{dia}$ (farelo de soja $16 \%$, farelo de trigo $37 \%$ e farelo de milho $47 \%$ ) e sal mineral para ovinos (Ovinofós Tortuga). O grupo tratado recebeu, além do volumoso, a monensina sódica fornecida na ração (Max Ovino Reprodução com monensina sódica - Rancho Alegre Produtos Agropecuários LTDA), $400 \mathrm{~g} / \mathrm{animal} /$ dia, e no sal mineral (Ovinofós com monensina - Tortuga), permitindo um consumo de $30 \mathrm{mg}$ por animal/dia. A água foi fornecida a ambos os grupos ad libitum. Com a finalidade de adaptação, a dieta foi oferecida às ovelhas 15 dias antes do início dos momentos de avaliação. Os 
grupos receberam a dieta até 30 dias após o parto. As ovelhas foram submetidas à observação clínica diária no decorrer do experimento e ao exame ultrassonográfico (Ultrassom GE, modelo Logic 100) para monitoramento. Os borregos foram pesados após o nascimento.

As colheitas das amostras de fluido ruminal, sangue e urina para exames laboratoriais foram efetuadas nos períodos de $60,50,40,30,20$ e 10 dias antes do parto (dap), no momento do parto e nos períodos 10,20 e 30 dias pós-parto (dpp).

As amostras de sangue foram colhidas no período da manhã, antes da oferta da primeira dieta do dia, por venopunção jugular com agulha $25 \times 8 \mathrm{~mm}$ em tubos siliconizados vacutainer com anticoagulante fluoreto de sódio/oxalato e, posteriormente, centrifugadas (Centrífuga Fanem Ltda Baby I, Mod. 206. Av. General Ataliba Leonel 1790, São Paulo, SP, Brasil) a 3000 g por dez minutos, para determinação da glicose. As amostras obtidas em tubos sem anticoagulante, para obtenção do soro, foram empregadas nas análises bioquímicas e hormonais. As amostras de soro e plasma foram divididas em alíquotas em tubos tipo eppendorf e armazenadas em ultrafreezer (Ultralow freezer NuAire Inc., 2100 Fernbrook Lane N. Plymouth, MN 55447, USA) a $-80^{\circ} \mathrm{C}$.

A urina foi obtida de forma espontânea para a pesquisa de corpos cetônicos utilizando-se fitas reagentes para urinálise (Uriquest Plus - Labtest Diagnóstica S.A., Av. Paulo Ferreira da Costa 600, Lagoa Santa, MG 33400-000, Brasil). As colheitas do fluido ruminal foram realizadas entre duas e quatro horas após a alimentação, num volume de aproximadamente $300 \mathrm{~mL}$ para cada animal, utilizando-se sonda oro-gástrica. Posteriormente, as amostras foram colocadas em garrafas térmicas previamente aquecidas e levadas ao laboratório, não ultrapassando o tempo de 15 minutos pós-colheita, para a realização das análises.

As variáveis mensuradas do perfil energético e proteico foram glicose, frutosamina, colesterol, triglicérides, proteína total (método do biureto), albumina (método do verde de bromocresol) e ureia (método enzimático). As leituras foram efetuadas a $37^{\circ} \mathrm{C}$ em analisador bioquímico semi-automático Labquest (Labtest Diagnóstica S.A., Av. Paulo Ferreira da Costa 600, Lagoa Santa, MG 33400-000, Brasil). $\beta$-hidroxibutirato (BHB) foi avaliado pelo método cinético enzimático e os ácidos graxos não esterificados (AGNEs) pelo método enzimático (Randox Laboratories Ltd, Ardmore, Diamond Road, Crumlin, Antrim, BT 29 4QY, UK). As determinações hormonais de cortisol e insulina foram realizadas pelo método de eletroquimioluminescência (Cobas e 411 - Roche Sistemas de Diagnósticos, Lda, Av. Eng. Billings 1729, Jaguaré, SP 05321- 900), utilizando-se reagentes comerciais (Elecsys Roche Diagnostics GmbH, D-68298 Mannheim, Germany).

No fluido ruminal foi determinado o pH (pHmetro: Corning 30) e a concentração dos ácidos graxos voláteis $(\mathrm{AGV})$. As amostras de fluido ruminal destinadas à mensuração dos $\mathrm{AGV}$ por cromatografia gasosa (Cromatógrafo gasoso - Espectometria de massa, GC-MS, Agilent Technologies, Califórnia, EUA $^{(11)}$ foram filtradas em cinco camadas de gaze e centrifugadas a 3000 g por 15 minutos; em seguida, o sobrenadante foi retirado e diluído em solução de ácido metafosfórico a 6\%, na proporção de 1:1, acondicionado em tubos tipo vials (Agilent Technologies, Califórnia, EUA) e armazenado em ultrafreezer a $-80{ }^{\circ} \mathrm{C}$.

Os valores obtidos foram analisados estatisticamente ao longo dos dez momentos experimentais, comparando-os entre si, e as variáveis estudadas foram submetidas à análise de variância. Os contrastes entre as médias foram realizados pelo teste de Tukey, calculando-se a diferença mínima significativa (dms) para $\alpha=0,05$. Para a análise não paramétrica, foram utilizados os métodos de Mann Whitney para amostras independentes e a prova de Friedman para amostras dependentes, usando o $\chi^{2}$. Foi realizada a determinação dos coeficientes de correlação de Pearson para verificar a relação entre pares de variáveis ${ }^{(12)}$. Empregou-se o programa computacional Sigma Stat 3.1. (SYSTAT Software, Inc. SigmaStat, SigmaPlot, SYSTAT are registered trademarks of Systat Software, Inc. 2004).

O projeto obteve parecer favorável da comissão de Ética no Uso de Animais (CEUA), da Universidade Federal Rural de Pernambuco com a licença n. 047/2013 CEPE/ UFRPE.

\section{Resultados e Discussão}

Todas as ovelhas tiveram parto normal, com 1,2 borregos /ovelha. Duas ovelhas do G1e uma do G2 
pariram gêmeos. Quanto ao peso dos borregos ao nascer, embora não tenha sido observada variação entre grupos $(\mathrm{P}>0,05)$, verificou-se que o dos nascidos das ovelhas que receberam a monensina foi $8,1 \%$ maior $(4,150 \mathrm{~g})$ em relação ao grupo controle $(3,840 \mathrm{~g})$. O escore corporal das ovelhas no início do trabalho estava entre 3,0 a 3,5 e ao final variou de 2,5 a 3,0 nos dois grupos.

Analisando-se a influência da monensina sódica sobre a concentração dos AGV no conteúdo ruminal ao longo dos momentos (pré-parto, parto e pós-parto), constatou-se que não ocorreram alterações nos valores dos ácidos acético e butírico nos momentos entre os grupos $(\mathrm{P}>0,05)$. Os valores do ácido propiônico mostraram-se mais elevados nos animais que receberam a monensina em todos os momentos. Entretanto, diferença significativa na concentração ruminal, entre os grupos, só foi observada no período pré-parto (40 dap) $(\mathrm{P}<0,05)$ (Figura 1). Ao longo dos momentos, em cada grupo, não foi encontrada diferenças $(\mathrm{P}>0,05)$ para os $\mathrm{AGV}$. A relação acetato:propionato foi menor no grupo tratado com a monensina em relação ao controle $(\mathrm{P}<0,001)$ (Quadro1). Esta modificação na fermentação ruminal e reflexo no padrão dos AGV, como resultado da ação da monensina, tem sido bem documentada. Este ionóforo seletivamente inibe o crescimento das bactérias Gram positivas e não o faz com as Gram negativas, devido a diferenças na estrutura da parede celular. O resultado desta mudança na população bacteriana tem gerado alguns impactos sobre o metabolismo dos ruminantes. A monensina modifica a proporção dos AGV no rúmen, aumentando a produção de ácido propiônico e reduzindo a de butírico e acético ${ }^{(07,13,14)}$. Estudos com bovinos, cabras de leite e ovinos consistentemente demonstraram elevação na concentração do propionato, mas nem sempre ocorreu diminuição nas concentrações de acetato e butirato ${ }^{(15-17)}$. Em contraste com os achados deste trabalho, Sauer et $\mathrm{al}^{(18)}$, Mousa ${ }^{(19)}$ e Aderinboye et al. ${ }^{(20)}$ encontraram, além da elevação de propionato, uma redução nas concentrações de acetato e butirato, sob ação da monensina.

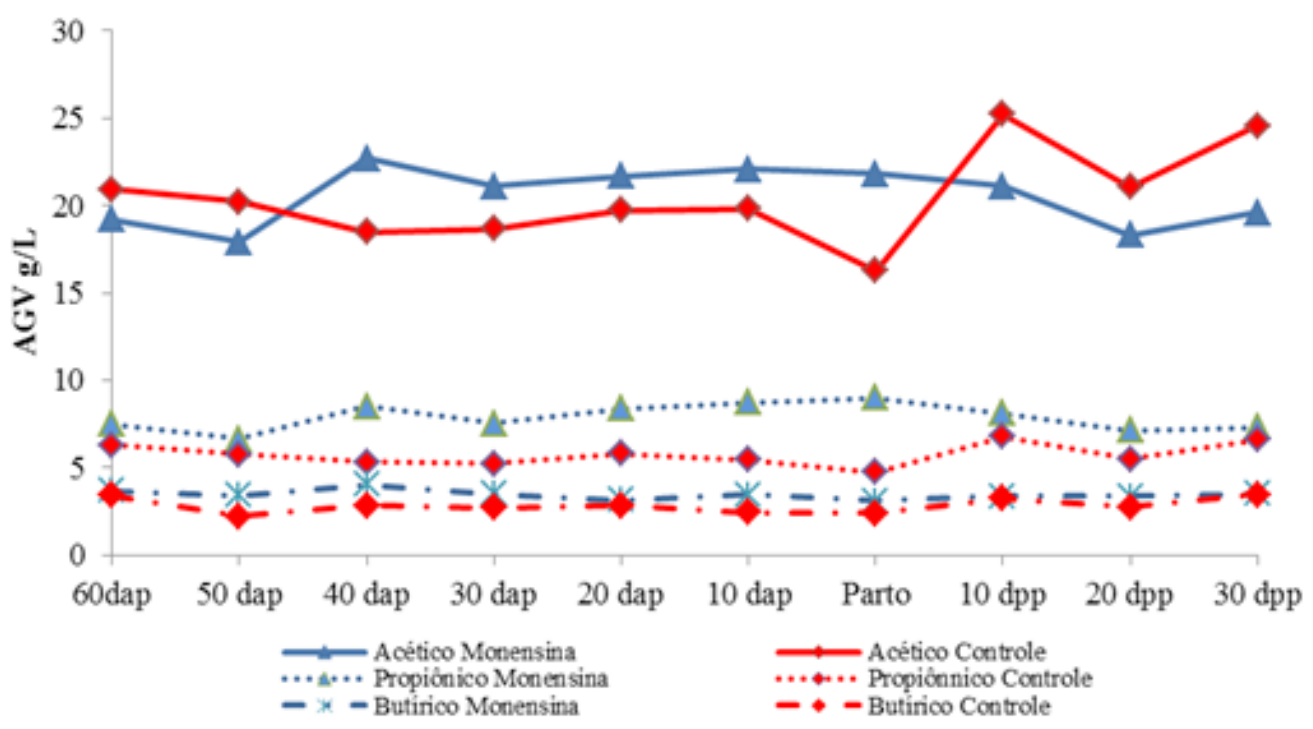

Figura 1: Valores médios dos ácidos graxos voláteis (AGV) (g/L) das ovelhas suplementadas com monensina sódica e do grupo controle, antes (dap), durante a após o parto (dpp).

Não foi observado efeito de grupo e de momento sobre $\mathrm{pH}$ ruminal (Quadro1). Mousa ${ }^{(19)}$ e Aderinboye et al. ${ }^{(20)}$ também não observaram variação no $\mathrm{pH}$ ruminal de caprinos suplementados com monensina. A estabilidade do $\mathrm{pH}$ ruminal pode ser atribuída à pouca variação na concentração dos AGV nos animais deste experimento. Estudos de Brown \& Hogue ${ }^{(16)}$ e Green et al. ${ }^{(17)}$, que estudaram com cabras e vacas, respectivamente, tratadas com monensina, registraram elevação do $\mathrm{pH}$ ruminal e atribuíram ao efeito benéfico da monensina inibindo a produção de ácido láctico pelas bactérias Gram positivas.

Ao avaliar os resultados dos valores obtidos para o AGNEs, foi constatada uma elevação ao longo 
dos momentos, em ambos os grupos, que foi significativa no décimo dia após o parto $(\mathrm{P}<0,002)$, em relação aos outros momentos, reduzindo-se em seguida. Não existiu efeito $(\mathrm{P}>0,05)$ da monensina sobre este componente ao longo dos períodos de observação, quando comparado ao grupo controle (Figura 2, Quadro 2). Estas diferenças ocorreram, provavelmente, devido ao balanço energético negativo nas ovelhas acontecido no período do pós-parto. Estes resultados destoam dos encontrados por Taghipoor et al. ${ }^{(10)}$, que relataram a influência deste ionóforo sobre o AGNEs no período do préparto, reduzindo a sua concentração. Acredita-se que tais distinções sejam justificadas pelo diferente tipo de dieta empregado nos trabalhos. As ovelhas no início da lactação requerem mais energia para síntese do leite do que durante a gestação e, inicio do período seco, há redução na ingestão de matéria seca ${ }^{(21,22)}$. Quando comparado ao presente estudo, resultados semelhantes foram descritos por Abe et al. ${ }^{(23)}$, Stephenson et al. ${ }^{(24)}$, Duffield et al. ${ }^{(25)} \mathrm{em}$ vacas de leite nas primeiras semanas após a parição. Esses autores relataram a pouca influência da monensina nesse período e justificaram seus achados pela menor concentração de gordura no leite das vacas tratadas com a monensina e a maior disponibilidade de glicose sanguínea, ocorrendo com isso menor oferta de AGNEs para a síntese da gordura pela glândula mamária.

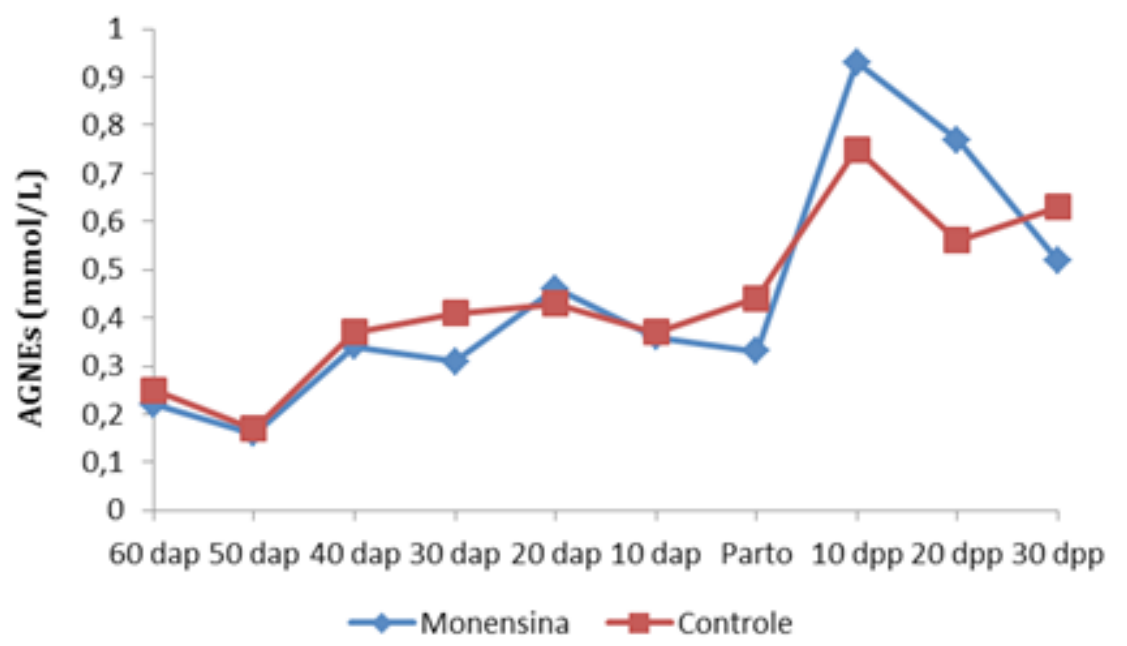

Figura. 2: Valores médios da concentração dos ácidos graxos não esterificados (AGNEs) (mmol/L) das ovelhas suplementadas com monensina sódica e do grupo controle, antes (dap), durante e após o parto (dpp).

Maiores médias na concentração de $\beta$-hidroxibutirato foram observadas no $10^{\circ} \mathrm{dpp}$ em relação aos demais dias do pré-parto, parto e pós-parto ( $\mathrm{P}<0,003)$, verificando-se valores de $0,70 \pm 0,12 \mathrm{mmol} / \mathrm{L}$ e $0,54 \pm 0,10 \mathrm{mmol} / \mathrm{L}$, nos grupos controle e monensina, respectivamente (Figura 3, Quadro 2). No contraste das médias entre grupos, verificaram-se diferenças da concentração de $\beta$-hidroxibutirato no período do parto $(\mathrm{P}<0,01)$ e no $10^{\circ} \mathrm{dpp}(\mathrm{P}<0,05)$, com os maiores valores encontrados no grupo controle em relação ao grupo monensina. Estes resultados são consistentes com os relatados por Duffield et al. ${ }^{(8,25,26)}$, Stephenson et al. ${ }^{(24)}$ e Zahra et al. ${ }^{(27)}$, que utilizaram a monensina em vacas de leite, por Austin \& Wild ${ }^{(9)}$ e Taghipoor et al. ${ }^{(10)}$ em ovelhas prenhas e por Sadjadian et al. ${ }^{(28)} \mathrm{em}$ cabras de leite. Acredita-se que os efeitos benéficos da monensina sobre o metabolismo energético ocorreu nestes períodos, devido à sua influência ao causar o balanço energético negativo, auxiliando, desta forma, a necessidade de manter o suprimento adequado de glicose para a unidade feto-placenta no final da gestação e no inicio da lactação, em que há maior demanda por glicose ${ }^{(29)}$. A redução na concentração de $\beta$-hidroxibutirato está, sobretudo, bem relacionada com o mecanismo de ação da monensina, que eleva a produção de propionato no rúmen, por modificar a composição da flora, 
preservando as Gram negativas, e deprimindo a síntese de butirato. O propionato é o maior precursor gliconeogênico que resulta em um maior aumento na produção de glicose e, com isso, há redução na produção de corpos cetônicos ${ }^{(18,30)}$. Nenhuma das ovelhas estudadas apresentou cetonúria. As concentrações de $\beta$-hidroxibutirato encontradas nos dois grupos assemelham-se a outros trabalhos, que são usados como indicador metabólico do estado nutricional considerado como adequado em ovelhas nas diferentes fases do ciclo reprodutivo e de manejo nutricional ${ }^{(29-34)}$.

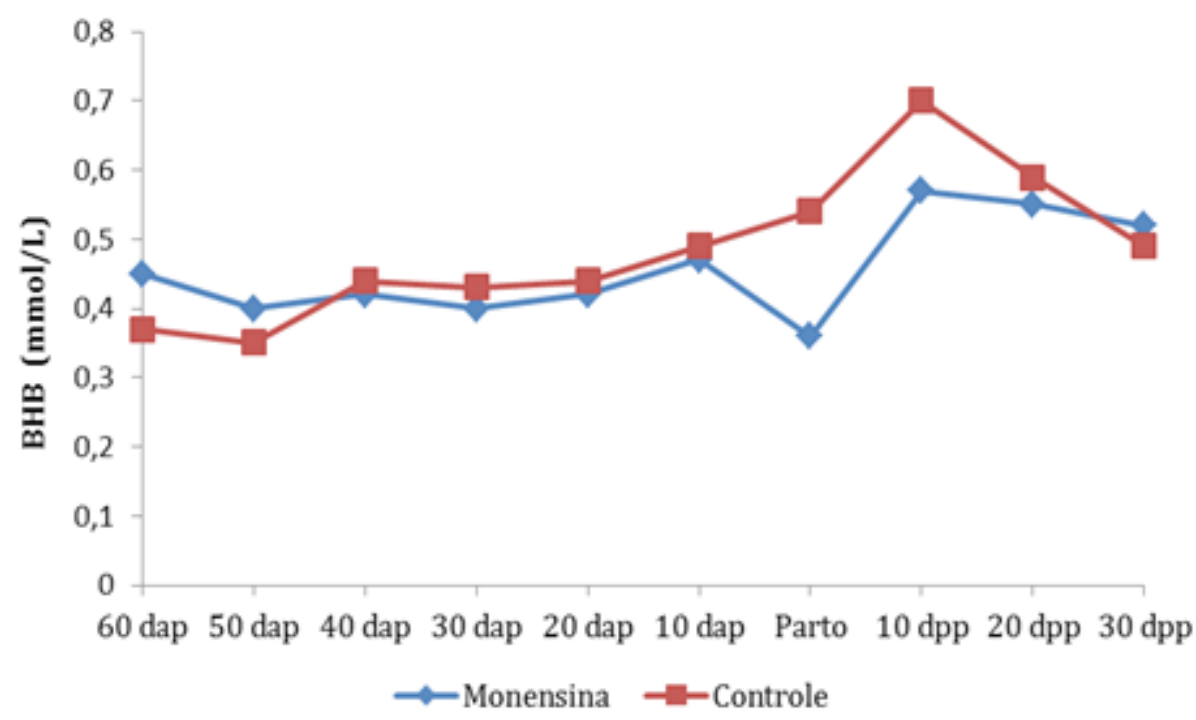

Figura 3: Valores médios da concentração do $\beta$-hidroxibutirato $(\mathrm{BHB})(\mathrm{mmol} / \mathrm{L})$ das ovelhas suplementadas com monensina sódica e do grupo controle, antes (dap), durante e após o parto (dpp).

Analisando os efeitos da monensina sobre a concentração da glicose ao longo dos períodos, entre os grupos, constatou-se que não houve diferença $(\mathrm{P}>0,05)$, embora a concentração tenha se mostrado mais elevada, na quase maioria dos momentos, nas ovelhas que receberam o ionóforo quando comparadas ao grupo controle (Figura 4, Quadro 2). Estes achados se assemelham aos relatados por Abe et al. ${ }^{(23)}$, Duffield et al. ${ }^{(25)}$, Plaizier et al. ${ }^{(35)}$, que analisaram o emprego da monensina em vacas durante o período de transição, por Taghipoor et al. ${ }^{(10)}$ em ovelhas no período do pré-parto e Sadjadian et al. ${ }^{(28)}$ em cabras de leite no período do periparto. Esta discreta alteração no perfil glicêmico, influenciada pela monensina, neste período, poderá ser justificada pelo maior estímulo na produção de insulina, provocado pelo aumento no fluxo glicogênico, que resultaria na diminuição nos valores de glicose plasmática nos animais tratados com o ionóforo, provavelmente pela maior participação da glicose no crescimento dos fetos, que é mais expressiva nesta fase da gestação ${ }^{(24)}$. Este fato foi constatado no peso das crias obtidas das ovelhas que receberam monensina, em que foi maior quando comparada ao grupo controle. Outra informação a ser considerada é que a glicose sofre pouca variação pelo aporte de energia na ração, uma vez que sua concentração sanguínea é regulada por um eficiente mecanismo hormonal destinado a manter constante a concentração deste componente metabólico ${ }^{(34)}$.

Entretanto, as informações de que o emprego da monensina aumenta a concentração de glicose têm sido consistentemente reportadas pela literatura. As elevações dos seus valores, com o uso deste antibiótico, foram relatadas em ovelhas no pré-parto por Austin e Wilde ${ }^{(09)} \mathrm{e}$ em vacas de leite no período do pós-parto por Green et al. ${ }^{(17)}$, Duffield et al. ${ }^{(26)}$ e Zahra et al. ${ }^{(27)}$. Esta ação é uma característica deste ionóforo, que altera o padrão da fermentação ruminal, elevando as concentrações de propionato, que resulta na maior produção de glicose, via ciclo do ácido cítrico ${ }^{(06,30)}$. A melhoria deste fluxo de propionato tem se mostrado bastante eficaz por causar modificações positivas no metabolismo energético em vacas ${ }^{(08)}$.

A elevação da glicose $(\mathrm{P}<0,007)$, em ambos os grupos, no momento do parto foi relatada por Santos et 
al. ${ }^{(36)}$, analisando o uso do propileno glicol e cobalto associado à vitamina B12 em ovelhas no período de transição, e por Araújo ${ }^{(37)}$, em ovelhas prenhas recebendo dieta de alta densidade energética. Este quadro de hiperglicemia momentânea, que surge em decorrência do estresse desencadeado no momento do parto, é justificado pela elevação das concentrações sanguíneas do hormônio cortisol ${ }^{(38)}$. Esta manifestação hormonal foi também verificada nas ovelhas no momento do parto, nos grupos monensina e controle $(\mathrm{P}>0,05)$, nas quais os valores alcançados foram de $97,38 \mathrm{nmol} / \mathrm{mL}( \pm 58,90) \mathrm{e}$ $74,81 \mathrm{nmol} / \mathrm{mL}( \pm 36,00)$, respectivamente (Figura 5, Quadro 2).

Maior concentração de frutosamina $(\mathrm{P}<0,03)$ foi observada no grupo das ovelhas que receberam monensina quando comparado com aquelas do grupo controle no $10^{\circ}$ dap, apresentando, respectivamente, valores de $186,45 \mu \mathrm{mol} / \mathrm{L}$ e $162,34 \mu \mathrm{mol} / \mathrm{L}$. Apesar de não existirem diferenças ( $\mathrm{P}>0,05)$, em ambos os grupos, os valores para esta variável foram mais elevados no período do pósparto, quando comparado aos demais (Figura 4, Quadro 2). Estes resultados mostraram-se superiores e diferentes no comportamento desta variável aos encontrados por Brito et al. ${ }^{(29)}$ e Filipovic et al. ${ }^{(39)}$ em ovelhas leiteiras durante o pré-parto e a lactação, principalmente neste último período estudado. Todavia, foram menores aos relatados por Carvalho ${ }^{(34)} \mathrm{em}$ ovelhas recebendo dietas com baixa e alta densidade energética, no respectivo período. A curva da concentração da frutosamina seguiu a mesma tendência da observada para a glicose, principalmente nos períodos do pré e pós-parto, sobretudo nas ovelhas que receberam a monensina. Embora seja significativa a relação entre estes indicadores, em todos os momentos, tais perfis apresentaram moderada relação $(r=0,37: P<0,04)$. Este comportamento da frutosamina, mais evidente nos animais tratados com a monensina, é justificado por sua característica, de ser uma proteína glicada estável, que depende da concentração média da glicose nas ultimas duas semanas e da meia vida das proteínas do sangue, principalmente albumina, e por isso não é influenciada por mudanças momentâneas do perfil glicêmico ${ }^{(39,40)}$. Diante desta condição, e por sua vez em que os valores da glicose, como já relatados, se mostraram mais elevados no grupo da monensina, e com poucas variações nos valores da albumina, mostrando-se com isso a existência de um melhor balanço energético neste grupo.

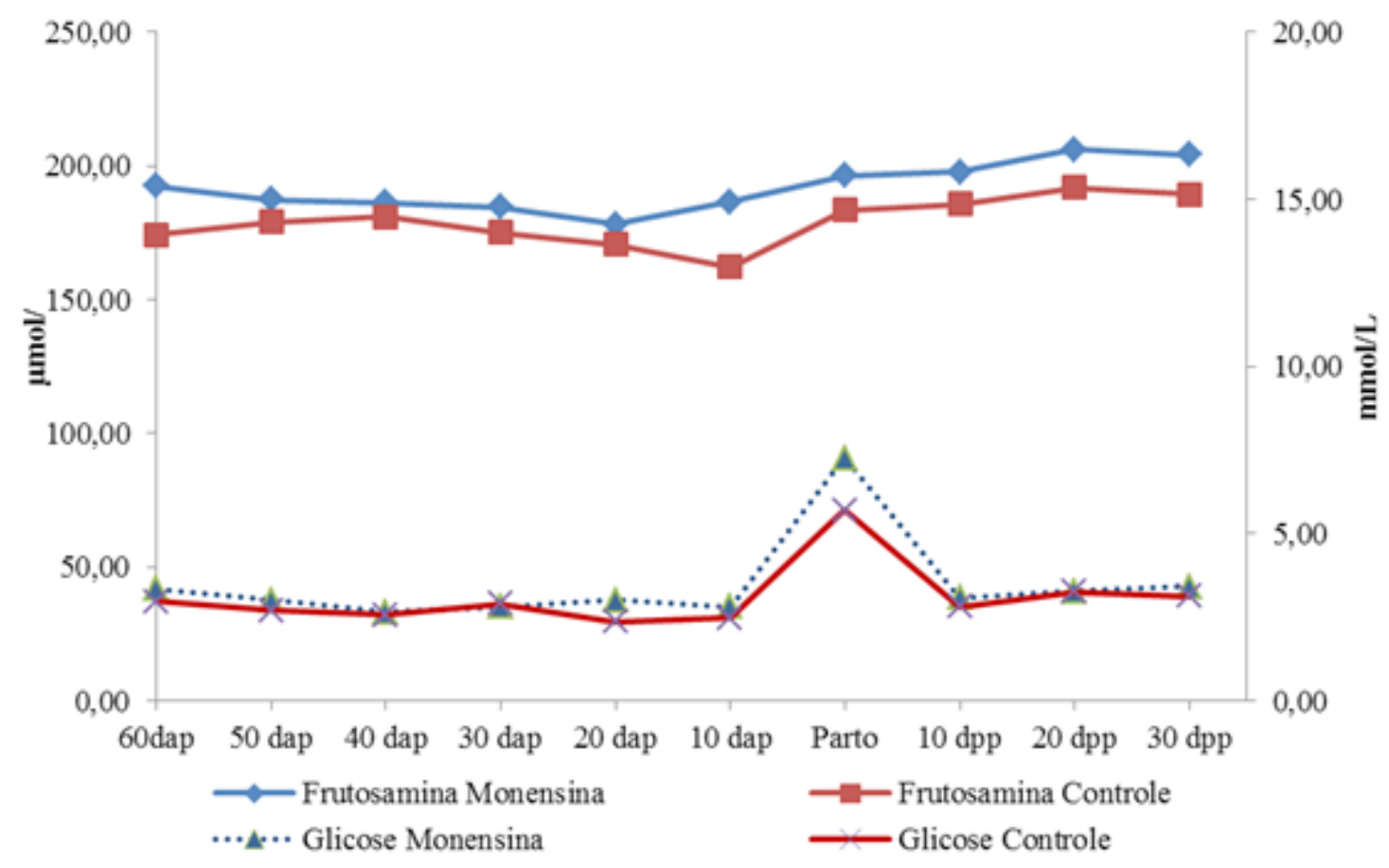

Figura. 4: Valores médios da glicose $(\mathrm{mmol} / \mathrm{L})$ e da frutosamina $(\mu \mathrm{mol} / \mathrm{L})$ das ovelhas suplementadas com monensina sódica e do grupo controle, antes (dap), durante e após o parto (dpp). 
Ao se ponderar os dados obtidos sobre a dinâmica do hormônio insulina, nos momentos estudados, verificou-se sua elevação $(\mathrm{P}<0,001)$ em ambos os grupos no momento do parto em relação ao pré e pós-parto. Foi constatado que os valores obtidos nas ovelhas do grupo monensina foram superiores em todo o período de observação, quando comparado com o controle, existindo diferenças $(\mathrm{P}<0,006)$ entre eles em quase todo pré-parto (50 dap, 40 dap, 20 dap, 10 dap), parto e 30 dpp (Figura 5, Quadro 2). Resultados semelhantes, empregando a monensina, foram relatados por Potter et al. ${ }^{(41)}$ e Raun et al. ${ }^{(42)}$ em bovinos, por Austin e Wilde ${ }^{(09)}$ em ovelhas prenhas e por Brown e Hogue ${ }^{(43)}$ em cabras de leite, os quais justificam, em comum, o comportamento deste hormônio, pela maior elevação da glicose constatada nos animais suplementados com o ionóforo. Esta informação foi bem retratada ao se verificar que existiu uma relação positiva destas variáveis, que foi alta no grupo monensina $(\mathrm{r}=0,79 ; \mathrm{P}<0,0001)$, enquanto para o controle foi considerada moderada $(\mathrm{r}=0,38 ; \mathrm{P}<0,003)$. Uma relação moderadamente positiva $(\mathrm{r}=0,39 ; \mathrm{P}<0,002)$ foi encontrada entre este hormônio e o cortisol nas ovelhas do grupo tratado pela monensina.

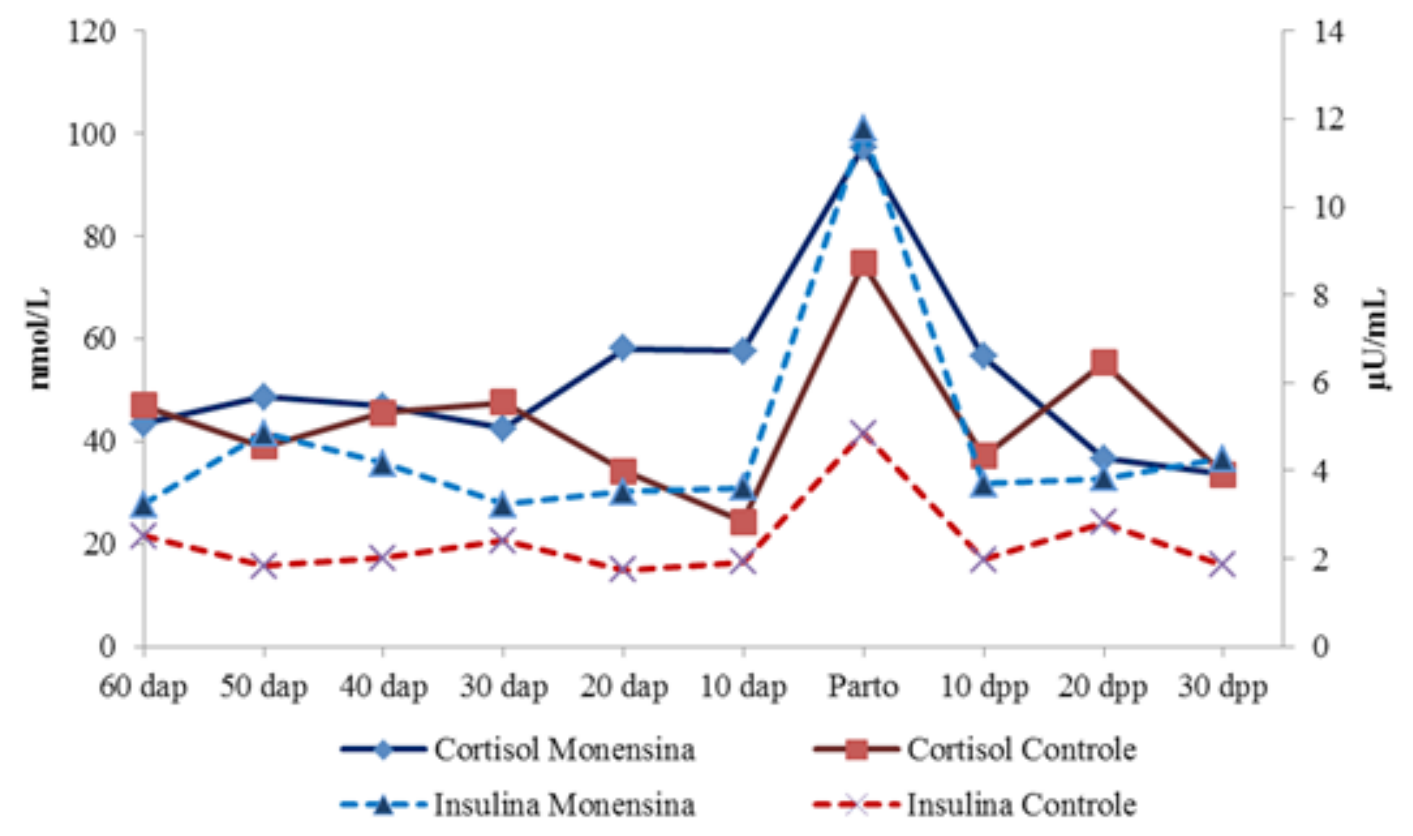

Figura 5: Valores médios da concentração dos hormônios cortisol ( $\mathrm{nmol} / \mathrm{L})$ e insulina $(\mu \mathrm{U} / \mathrm{mL})$ das ovelhas suplementadas com monensina sódica e do grupo controle antes (dap), durante e após o parto (dpp).

$\mathrm{Na}$ análise do colesterol sérico não ocorreu efeito de momento e nem de grupo ( $\mathrm{P}>0,05)$, estando os valores dentro da faixa de normalidade para a espécie ovina, de acordo com Ribeiro et al. ${ }^{(33)}$, que trabalharam com ovelhas durante a gestação e a lactação, e Kaneko et al. ${ }^{(38)}$ (Figura 6, Quadro 2). Os resultados foram semelhantes aos encontrados por Taghipoor et al. ${ }^{(11)} \mathrm{em}$ ovelhas prenhas e por Sadjadian et al. ${ }^{(28)}$ em cabras leiteiras no periparto, empregando a monensina na dieta. Todavia, divergem dos resultados encontrados por Duffield et al. ${ }^{(25)}$, que avaliou o efeito da monensina em vacas leiteiras no período de transição e relataram concentrações mais altas do colesterol sérico, sendo justificado devido à maior liberação de lipoproteínas a partir do fígado. Outra informação a se considerar foi relatada por Balikci et al. ${ }^{(44)}$, que descreveram, em ovelhas, o aumento gradual do colesterol e triglicérides no final da gestação, em decorrência das concentrações de insulina, a qual atua diretamente no metabolismo do tecido adiposo durante a gestação, e a diminuição da resposta 
do tecido-alvo ao hormônio no final da gestação predispõe as ovelhas à elevação das concentrações destes componentes e das lipoproteínas.

Com relação à concentração dos triglicerídeos, não houve efeito entre os grupos $(\mathrm{P}>0,05)$; contudo, efeito de momento foi constatado no grupo controle $(\mathrm{P}<0,05)$, com elevação aos 20 dap em relação ao pós-parto e no grupo monensina $(\mathrm{P}<0,05)$ a maior média foi obtida aos 30 dap em relação ao parto e pós-parto. Em ambos os grupos, em relação aos demais momentos, os menores valores de triglicérides foram no pós-parto (Figura 6, Quadro2). Analisando o perfil bioquímico em cabras leiteiras, Mundim et al. ${ }^{(45)}$ relataram que valores inferiores de triglicérides observados no final da gestação e início da lactação podem ser justificados pelo aumento da produção de leite, a menor disponibilidade de ácidos graxos, a lipólise para obtenção de energia e do maior aporte de triglicérides circulantes para a glândula mamária para síntese de gordura do leite. Resultados semelhantes foram encontrados por Taghipoor et al. ${ }^{(10)}$, em estudo com ovelhas prenhes, e por Sadjadian et al. ${ }^{(28)}$, que avaliaram o perfil metabólico de cabras leiteiras, com a administração da monensina, e relataram não ter ocorrido alteração dos valores de triglicerídeos pelo uso do ionóforo.

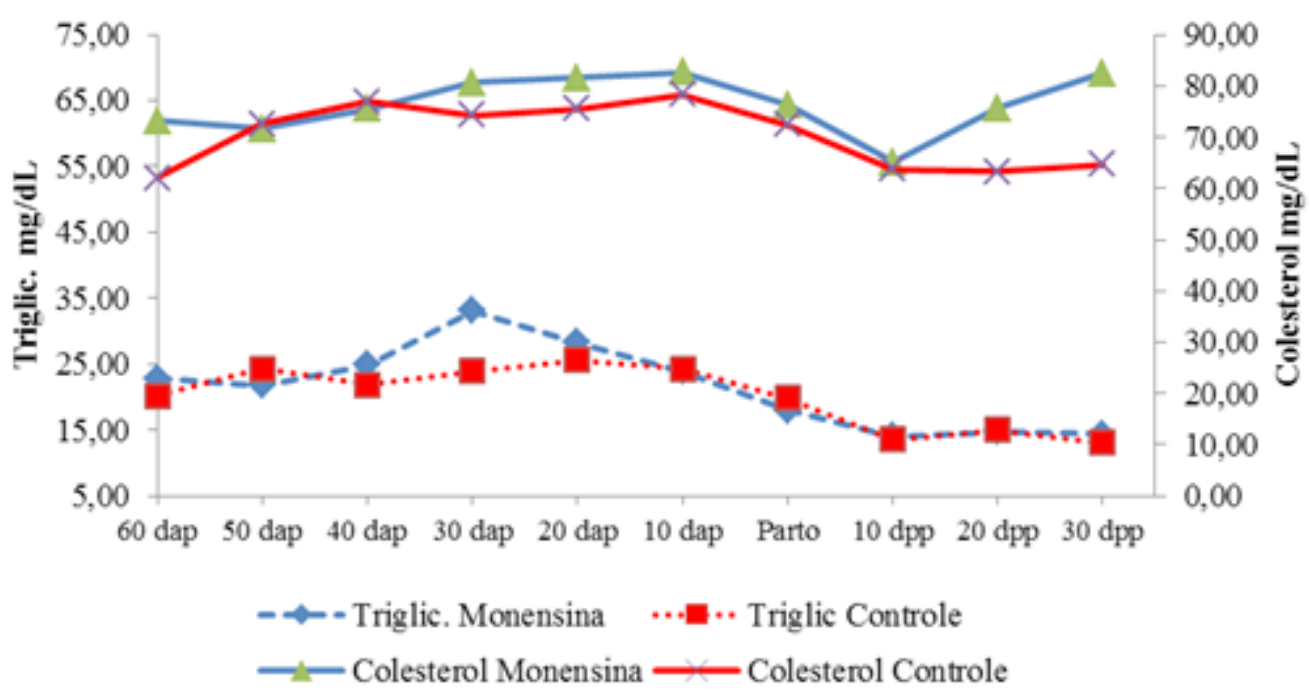

Figura 6: Valores médios da concentração dos triglicerídeos e do colesterol (mg/dL) das ovelhas suplementadas com monensina sódica e do grupo controle antes (dap), durante e após o parto (dpp).

Ao longo dos períodos analisados, não foi encontrado efeito $(\mathrm{P}>0,05)$ da monensina para os indicadores proteicos (proteína total, albumina e ureia) (Quadro 2). Resultados semelhantes foram obtidos por Austin e Wilde ${ }^{(09)}$, Taghipoor et al. ${ }^{(10)}$ e Sadjadian et al. ${ }^{(28)}$, em ovelhas e cabras de leite. Entretanto, destoaram para os índices da ureia dos resultados encontrados por Stephenson et al. ${ }^{(24)}$, Duffield et al. ${ }^{(25,26)}$ e Zahra et al. ${ }^{(27)}$, em bovinos suplementados com a monensina. Nesses animais, justifica-se o alto valor obtido como provável resultado de um maior suprimento de proteína by-pass, uma vez que a monensina causa uma redução na degradação da proteína no rúmen e com isso proporciona maior disponibilidade ao intestino delgado ${ }^{(6,46)}$. 


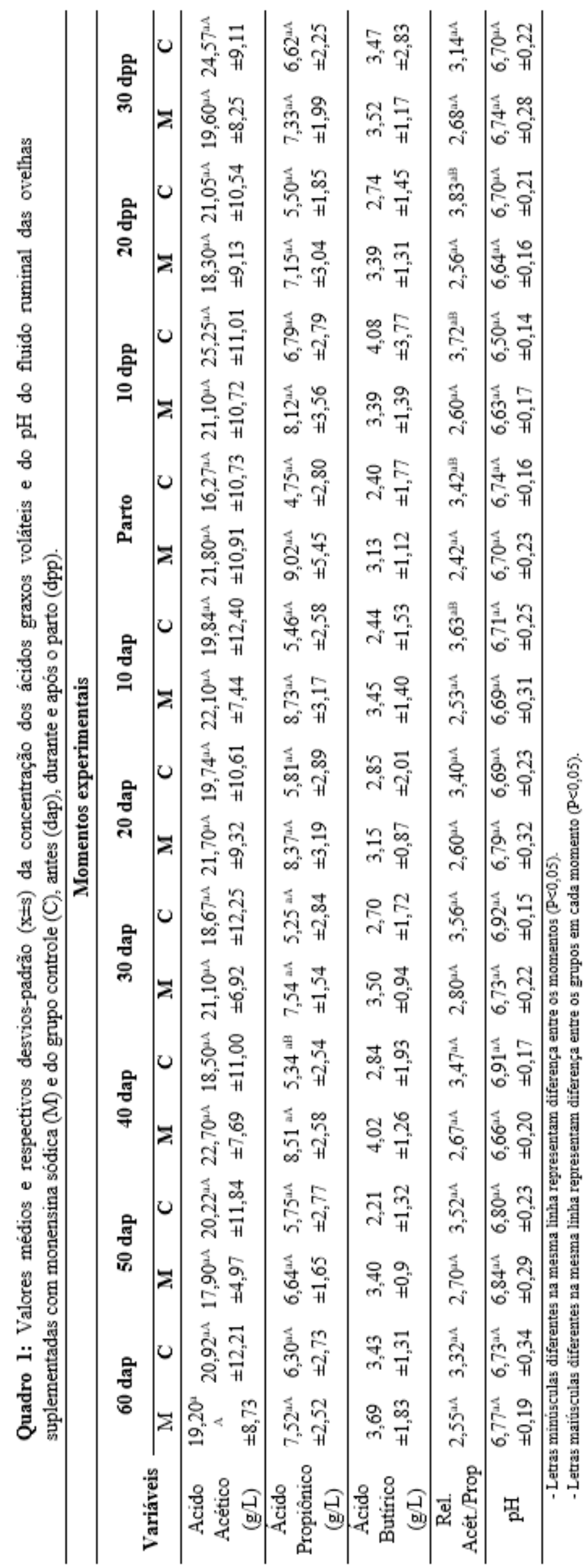




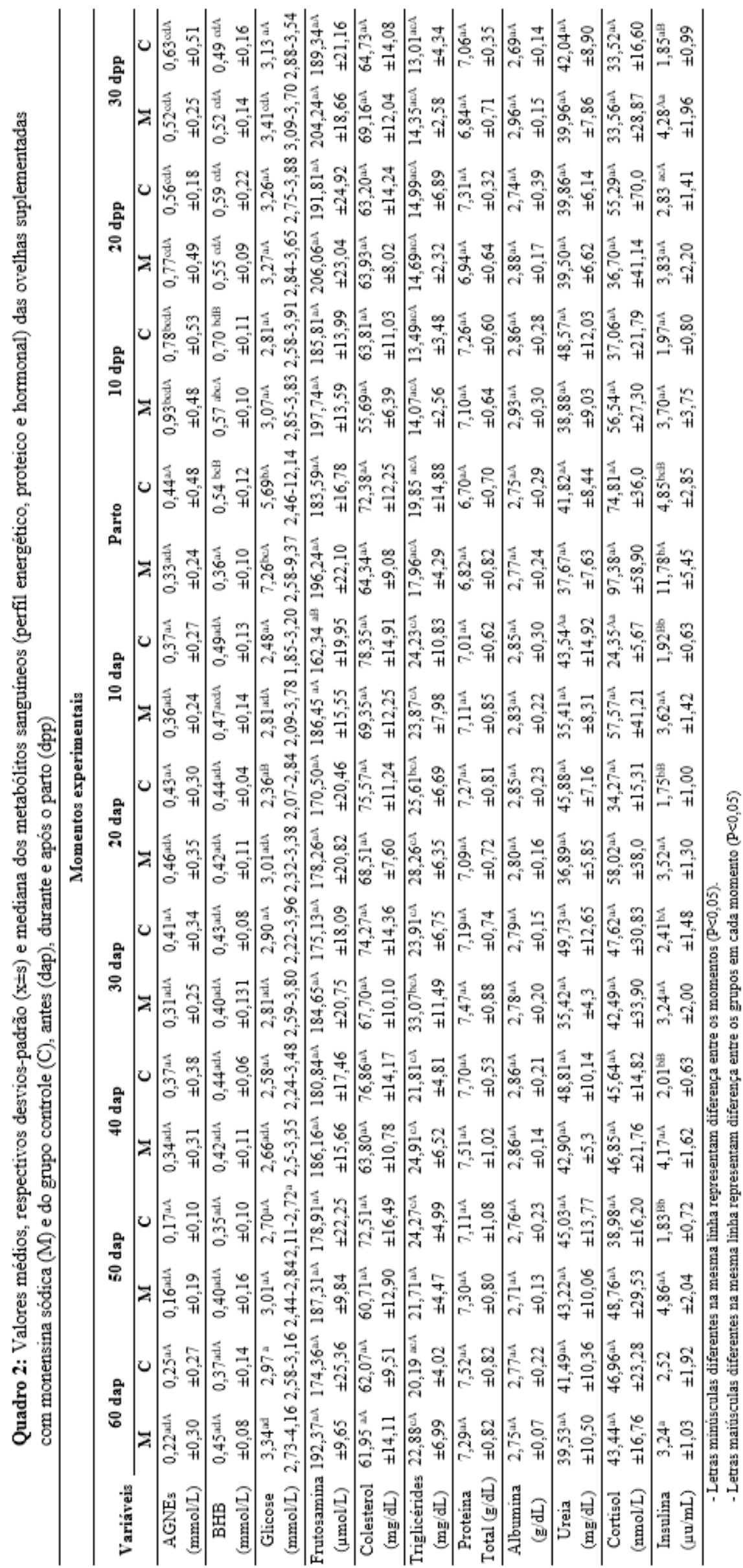




\section{Conclusão}

Este estudo demonstrou que a monensina sódica, ofertada às ovelhas antes, durante e após o parto, influencia positivamente os indicadores metabólicos energéticos e hormonais, destacando-se a frutosamina e a insulina. Com isso, o uso desse ionóforo se mostra promissor em influenciar no status energético das ovelhas neste período, gerando boa perspectiva na prevenção de transtornos metabólicos, como a toxemia da prenhez, comum nesta espécie animal durante este período.

\section{Agradecimentos}

À Fundação de Amparo à Ciência e Tecnologia do Estado de Pernambuco (FACEPE) pela concessão da Bolsa de Mestrado (IBPG n ${ }^{\circ} 0086-5.05 / 11$ ), ao CNPq pelo auxílio financeiro (Edital Universal 14/2011, processo $n^{\circ} 473104 / 2011-3$ ), à CAPES (PROCAD NF - 2009/362-10) pelo apoio na formação dos recursos humanos, ao Instituto Tecnológico de Pernambuco (ITEP) pela realização da cromatografia gasosa e ao Hospital Militar de Área do Recife - HMAR pelas dosagens hormonais.

\section{Referências}

1. Afonso J.A.B. Doenças carenciais e metabólicas e sua influência na exploração de caprinos e ovinos. In: Anais do I Seminário Norte-Rio Grandense de Caprinocultura e Ovinocultura, 1, Mossoró. 2005; p.1-10.

2. Campos R., González F., Coldebella A., Lacerda L. Indicadores do metabolismo energético no pós-parto de vacas leiteiras de alta produção e sua relação com a composição do leite. Ciênc. Anim. Bras. 2007; 8: 241-249.

3. Ortolani E. L., Benesi, F. J. Ocorrência de toxemia da prenhez em cabras (Capra hircus, L) e ovelhas (Ovis aries, L) criadas no estado de São Paulo, Brasil. Revta. Fac. de Méd. Vet. e Zootec. 1989; 26: 229-234.

4. Campos A.G.S., Afonso J.A.B., Dantas A.C., Santos R.A., Guimarães J.A., Mendonça C.L. Estudo clínico da toxemia da prenhez em ovelhas: análise de 33 casos. Ciênc. Anim. Bras. 2010; 11: 623-628.

5. Santos F.C., Mendonça C.L., Silva Filho A.P., Carvalho C.C.D., Soares P.C., Afonso J.A.B. Indicadores bioquímicos e hormonais de casos naturais de toxemia da prenhez em ovelhas. Pesq. Vet. Bras. 2011; 31: 974980.

6. Bergen W.J., Bates D.B. Ionophores: their effect on production efficiency and mode of action. J. of Anim. Sci. 1984; 58: 1465-1483.

7. Schelling G.T. Monensin mode of action in the rumen. J. Anim. Sci. 1984; 58: 1518-27.

8. Duffield T.F., Rabiee A., Lean I.J. Overview of meta-analysis of monensin in dairy cattle. Vet. Clin. Food Anim. 2012; 28: 107-119.

9. Austin A. R., Wilde R.M. The effect of sodium monensin on pregnant ewes. Br. Vet. J. 1985; 141: 628-634.

10. Taghipoor B., Seifi H., Mohri M., Farzaneh N., Naserian A.A. Effect of prepartum administration of monensin on metabolism of pregnant ewes. Livest. Sci. 2011; 135: 231-237.

11. Carlsson J. Simplified gas chromatographic procedure for identification of bacterial metabolic products. Appl. Microbiol. 1973; 25: 287- 289.

12. Curi P.R. Metodologia e Análise da Pesquisa em Ciências Biológicas. Botucatu: Tipomic; 1997.

13. Nagaraja T.G., Taylor M.B. Susceptibility and resistance of ruminal bacteria to antimicrobial feed aditives. Appl. Environ. Microbiol. 1987; 53:1620-1625.

14. Russel J.B., Strobel H.J. Effect of ionophores on ruminal fermentacion. Appl. Environ. Micro. 1989; 55: $1-6$.

15. Rowe J.B., Davies A, Broome A.W.J. Quantitative changes in the rumen fermentation of sheep,associated with feeding monensin. Proc. Nutr. Soc. 1981; 41:3A.

16. Brown D.L., Hogue D.E. Effects of feeding monensin sodium to lactating goats: milk composition and 
ruminal volatile fatty acids. J. Dairy Sci. 1985; 68: 1141-1147.

17. Green B.L, McBride B.W., Sandals D., Leslie K.E., Bagg R., Dick P. The Impact of a Monensin ControlledRelease Capsule on Subclinical Ketosis in the Transition Dairy Cow. J. Dairy Sci. 1999; 82: 833-842.

18. Sauer F.D., Kramer J.K.G., Cantwell W.J. Antiketogenic Effects of Monensin in Early Lactation. J. Dairy Sci. 1989; 72: 436-442.

19. Mousa H.M. Ruminal and blood characteristics of nubian goats dosed with the growm promoter monensin. Acta Vet. Brno. 1994; 63: 13-17.

20. Aderinboye R.Y., Onwuka C.F.I., Arigbede O.M., Oduguwa O.O., Aina A.B.J. Effect of dietary monensin inclusion on performance, nutrient utilisation, rumen volatile fatty acid concentration and blood status of West African dwarf bucks fed with basal diets of forages. Trop. Anim. Health Prod. 2012; 44: 1079-1087.

21. Abdelrahman M.M., Abo-Shehada, M.N., Mesanat, A., Mukbel, R. The requirements of calcium by Awassi ewes at early lactation. Small Rumin. Res. 2002; 45: 101-107.

22. Karapehlivan M., Atakisi E., Atakisi O., Yucayurt R., Pancarci S.M. Blood biochemical parameters during the lactation and dry period in Tuj ewes. Small Rumin. Res. 2007; 73: 267-271.

23. Abe N., Lean I.J., Rabiee A., Porter J., Graham C. Effects of sodium monensin on reproductive performance of dairy cattle. II. Effects on metabolites in plasma, resumption of ovarian cyclicity and oestrus in lactanting cows. Austral. Vet. J. 1994; 71: 277-282.

24. Stephenson K.A., Lean I.J., Hyde M.L., Curtis M.A., Garvin J.K., Lowe L. B. Effects of monensin on the metabolism of periparturient dairy cows. J. Dairy Sci. 1997; 80: 830-837.

25. Duffield T.F., LeBlanc S., Bagg R., Leslie K., Ten Hag J., Dick P. Effect of a monensin controlled release capsule on metabolic parameters in transition dairy cows. J. Dairy Sci. 2003; 86: 1171-1176.

26. Duffield T.F.,Sandals D., K. E. Leslie K.E., Lissemore K., McBride B. W., Lumsden J. H., Dick P., Bagg R. Effect of prepartum administration of monensin in a controlled-release capsule on postpartum energy indicators in lactating dairy cows. J. Dairy Sci. 1998; 81: 2364-2361.

27. Zahra L.C., Duffield T.F., Leslie K.E., Overton T.R., Putnam D., LeBlanc S. J. Effects of Rumen-Protected Choline and Monensin on Milk Production and Metabolism of Periparturient Dairy Cows. J. Dairy Sci. 2006; 89: 4808-4818.

28. Sadjadian R., Seifi H.A., Mobri M., Naserian A.A., Farzaneh N. Effect of monensin on metabolism and production in dairy Saanen goats in periparturient period. Asian Aust. J. Anim. Sci. 2013; 26: 82-89.

29. Brito M.A., González F.D., Ribeiro L.A., Campos R, Lacerda L., Barbosa P.R., Guiomar B. Composição do sangue e do leite em ovinos leiteiros do sul do Brasil: variações na gestação e na lactação. Cienc. Anim. Bras. 2006; 36: 942-948.

30. Richardson L.F., Raun A.P., Potter E.L., Cooley C.O., Rathmacher R.P. Effect of monensin on rumen fermentation "in vitro" and "in vivo". J. Anim. Sci. 1976; 43: 657-664.

31. Russel A.J.F., Maxwell T.J., Sibbald A.R., Mc Donald, D. Relationships between energy intake, nutritional state and lamb birth weight in Grayface ewes. J. Agric. Sci. 1977; 89: 667-673.

32. Robinson J.J. Energy requirements of ewes during late pregnancy and early lactation. Vet. Rec. 1980; 106: 282-284.

33. Ribeiro L.A.O., Mattos R.C., Gonzalez F.H.D., Wald V.B., Silva M.A., La Rosa V.L. Perfil metabólico de ovelhas Border Leicester x Texel durante a gestação e a lactação. Revta. Port. Ciênc. Vet. 2004; 99: 155-159.

34. Carvalho C.C.D. Indicadores preditivos para o diagnóstico da toxemia da prenhez em ovelhas. Tese de Doutorado em Ciência Veterinária, Universidade Federal Rural de Pernambuco, Recife, PE. 2013.177p. http:// bdtd.ibict.br/vufind/Record/URPE_269615e5534fd45220523755174ea2d3.

35. Plaizier J.C, Fairfield A. M., Azevedo P.A., Nikkhah A., Duffield T.F., Crow G. H., Bagg R., Dick P. McBride B. W. Effects of Monensin and Stage of Lactation on Variation of Blood Metabolites Within TwentyFour Hours in Dairy Cows. J. Dairy Sci. 2005; 88: 3595-3602.

36. Santos R.A., Campos A.G.S.S., Afonso J.A.B., Soares P.C., Mendonça C.L. Efeito da administração de propileno glicol e cobalto associado à vitamina B12 sobre o perfil metabólico e a atividade enzimática de ovelhas da raça Santa Inês no periparto. Pesq. Vet. Bras. 2012; 32(Supl.1): 60-66. 
37. Araujo C.A.S.C., Nikolaus J.P., Morgado A.A., Monteiro B.M., Rodrigues F.A.M.L., Vechiato T.A.F., Soares P.C., Sucupira M.C.A. Perfil energético e hormonal de ovelhas Santa Inês do terço médio da gestação ao pós-parto. Pesq. Vet. Bras. 2014; 34(12):1251-1257.

38. Kaneko J.J., Harvey J.W., Bruss M.L. Clinical Biochemistry of Domestic Animals. 6th ed., New York: Academic Press; 2008.

39. Filipovic N., Stojevic Z., Masek T., Mikulec Z., Prvanovic N. Relationship between fructosamine with serum protein, albumin and glucose concentrations in dairy ewes. Small Rumin. Res. 2011; 96: 46-48.

40. Armbruster D. A. Fructosamine: structure, analysis, and clinical usefulness. Clin. Chem. 1987; 33: 21532163.

41. Potter E.L., Cooley C.O., Richardson L.F., Raun A.P. \& Rathmacher R.P. Effect of monensin on performance of cattle forage. J. Anim. Sci. 1976; 43: 665-669.

42. Raun A.P., Cooley C.O., Potter E.L., Rathmacher R.P., Richardson L.F. Effect of monensin on feed efficiency of feedlot cattle. J. Anim. Sci. 1976; 43: 670-677.

43. Brown D.L. \& Hogue D.E. Effects of feeding monensin to lactating goats: acetyl coenzyme A carboxylase, hormone-sensitive lipase, plasma glucose and circulating hormones. J. Dairy Sci. 1987; 70: 823-830.

44. Balikci E., Yildiz E., Gürdoğan F. Blood metabolite concentrations during pregnancy and postpartum in Akkaraman ewes. Small Rumin. Res. 2007; 67: 247-251.

45. Mundim A.V., Costa A.S., Mundim S.A.P., Guimarães E.C., Espindola F.S. Influência da ordem e estágio da lactação no perfil bioquímico sanguíneo de cabras da raça Saanen. Arq. Bras. Med. Vet. e Zoot. 2007; 59: 306-312.

46. Afonso J.A.B., Mendonça C.L., Fioravanti M.C.S., Kuchembuck M.R.G. Características e indicações clínicas dos ionóforos para ruminantes. J. Conselho Fed. Med. Vet. 2000; 5: 29-36. 